\title{
1025 TUNE INTO TRAFFIC - EARPHONE ADVERT
}

M Darroch* Correspondence to Youth for Road Safety - YOURS, 32 St Annes Road, Willenhall West Midlands, wv13 1ed, UK

10.1136/ip.2010.029215.1025

Road traffic collisions are the biggest threat to young people's lives in the UK. Statistics indicate that a young people aged $15-24$ is more likely to be killed by traffic than being stabbed abused or neglected. This issue is not just a matter affected young people in the UK but is a global health concern highlighted by the WHO. In contemporary society, young people are particularly vulnerable to road traffic accidents and research has shown that brain development in young people is in most cases the cause of the problem for young people. Hazard perception development in the frontal cortex of the brain is underdeveloped in young people until the age of 25, in this case, young people are more likely to be distracted on the road. Tune into Traffic is a campaign aiming to revamp the old Green Cross Code of Stop Look and Listen. In the UK, every young person hold preference to music and in using music to address a road safety concern, we have produced an internet and cinema advert that focuses on the danger of listening to music while using the road. This is of particular importance as the usage of iPods and MP3 players has increased significantly with young people. Our advert, in an extremely short and succinct manner puts forward the issue and presents a solution. In showing this to organisations such as - Youth for Road Safety (YOURS), the UK Youth Parliament, The Royal Society for the Prevention of Accidents, the response has been extremely positive and we are pushing on releasing the advert on TV after being successful on social media websites. 